\title{
1 UNdERSTANDING TURbULENT KinETIC ENERgY (TKE) STATIONARITY WITHIN A FOREST
}

2 CANOPY.

3 April L. Hiscox ${ }^{1}$, Mark Rudnicki ${ }^{2}$, and David R. Miller ${ }^{3}$

4

$5 \quad{ }^{1}$ University of South Carolina, Department of Geography

$6 \quad{ }^{2}$ Michigan Technological University, School of Forestry

$7 \quad{ }^{3}$ The University of Connecticut, Department of Natural Resources and Environment

8

9

10 Corresponding Author:

11 April Hiscox

12 hiscox@sc.edu

13 phone: $803-777-6604$

14 Fax: 803-777-4792

15

16 


\section{Abstract}

18 Year round measurements of turbulence were taken at heights, above, below, and in the live

19 crown in an old-growth forest in Howland, ME. A technique to determine the stationarity of

20 turbulence kinetic energy (TKE) is presented and used as a classifier of the turbulence

21 intermittency in the nocturnal boundary layer. The results show that both the length of a

22 stationary TKE signal and the scale of intermittency vary with canopy depth. TKE remains

23 stationary for longer periods above the canopy, and shorter periods are observed in the open

24 space below the live crown. Neutral stability conditions exhibit the highest intermittency at all

25 heights. Additionally a new intermittency factor is introduced which allows for characterizing

26 turbulent regimes. The results have broader implications for understanding and identifying

27 turbulent statistics in the stable boundary layer.

\section{1. Introduction}

29 Forests play a large and vital role in global carbon and water budgets. Therefore, a

30 fundamental understanding of the mechanisms that control energy and mass exchange between

31 the atmosphere and forested ecosystems is of key importance. While much work has focused on

32 the coupling of the turbulence above and below canopies during unstable daytime conditions

33 (e.g. Vickers and Thomas 2013), less is known about stable nighttime conditions in these

34 environments (Aubinet 2008; Mahrt 2010; Mahrt et al. 1998). Additionally, much of our current

35 understanding of scalar fluxes is grounded in long-term eddy covariance measurement methods

36 (Baldocchi 2003). These methods, however, are less reliable at night during stable stratification

37 (Aubinet 2008). Understanding forest-atmosphere exchanges at night is important for practical 
applications such as turbulence and wind modeling (Finnigan et al. 2009), eddy covariance

39 quality control techniques, and quantification of ecosystem exchange (Baldocchi 2003).

One area of particular interest is the subject of intermittency in the stable boundary layer

41 (SBL) (examples include: Liang et al. 2014; Salmond 2005; Sun et al. 2012; Sun et al. 2013; Sun

42 et al. 2004; Van de Wiel et al. 2002a; Van de Wiel et al. 2002b). Possible sources of

43 intermittency have been identified as density currents (Sun et al. 2002), mesoscale wind gusts

44 penetration downward into the stable surface layer (Sun et al., 2004), low-level jets (Prabha et al.

45 2007), turbulence-wave interaction (Mahrt, 2014), and flow interaction with complex topography

46 (Cava, et al., 2005). Many of these studies have focused on the possible sources of

47 intermittency, or on classifying intermittency regimes. More recently, a broader theoretical

48 understanding of the persistence of the mean flow and conditions necessary to sustain turbulence,

49 and turbulent mixing, has started to take shape (e.g. Van de Wiel et al. 2012). The addition of a

50 forest canopy, an environment where flow is regularly disturbed by vegetation elements and

51 canopy gaps, complicates the previously proposed intermittent classification schemes. Recently,

52 Vickers and Thomas (2013) have made a detailed evaluation of the various terms in the turbulent

53 kinetic energy (TKE) tendency equation, and concluded that subcanopy turbulence is driven by

54 shear generation above the canopy, further confirming previous work (e.g. Dwyer et al., 1997;

55 Leclerc et al., 1990; Lesnik, 1974; Meyers and Baldocchi, 1991, and others). This is a strong

56 indication of a coupling between the two layers (Belcher et al., 2012; Lee, 2000; Mahrt et al.,

57 2000). However, in stable conditions evidence of decoupling has been reported, particularly

58 associated with wind shears (Alekseychik et al. 2013).

59 At the core of micrometeorological measurements is the direct measurement of

60 turbulence with sonic anemometers. To determine fluxes of heat, momentum and other scalars, it 
61 is assumed that the first-, and sometimes second-, order statistics of the turbulent field are

62 stationary. This assumption, however, which is fundamental to our understanding of turbulence,

63 is often not valid. If it is valid, it only holds for short periods of time, generally assumed to be 30

64 minutes or less. This is particularly true in the weak wind conditions which can dominate stable

65 conditions (Cullen et al. 2007). It is also known that the assumption of stationarity does not

66 always hold true in the atmospheric surface layer (ASL). To address these issues, several

67 different tests for stationarity have been developed and used to quality control data (Foken and

68 Wichura 1996; Mahrt 1998). More recently Cava et al. (2014) have proposed a combined

69 stationarity index for this purpose and concluded that stable conditions have the most ambiguity

70 in determining stationarity.

71 Work by Nappo et al. (2010) has shown the potential of durations of turbulence stationarity as

72 a classifier of the turbulence regimes in the stable boundary layer. In other words, how long a

73 time series stays time-invariant is a classifier of overall levels of turbulence. In a homogeneous

74 environment (Nappo et al. 2010) a correlation exists between the duration of stationarity and the

75 kurtosis of heat flux within the stable surface layer, but a poor association is evident between the

76 two above the surface layer. Therefore, the examination of how long turbulent variables remain

77 stationary can enhance our full understanding of how these changes affect measured fluxes in

78 different surface environments. Furthermore, identifying how long a variable stays stationary

79 can help separate the events which happen at mixed scales. We present here the application of

80 this technique to a non-homogeneous forest environment to quantify stationarity of turbulence

81 regimes at different levels within the canopy, and second identify potential couplings of non-

82 stationarity and intermittency in this environment. In addition we propose a new intermittency

83 factor as a method of classifying nocturnal turbulence regimes. 


\section{2. Methods}

85 Data were collected at the Howland Research Forest in Howland, Maine, which consists 86 mostly of an old growth Spruce/Fir forest. Mean canopy height in the study plot is 20.6 meters.

87 The site is part of the AMERIFLUX network, site US-Ho2. Detailed canopy information can be

88 found in Hollinger et al. (1999) and Xiao et al. (2004). Three CSAT3 sonic anemometers

89 (Campbell Scientific, Inc. Logan, UT) were installed on the Howland West tower: one just

90 above the canopy top $(21.4 \mathrm{~m})$, one at the center of the live crown $(15.1 \mathrm{~m})$ and one just below

91 the live crown $(8.0 \mathrm{~m})$. These heights were chosen to correspond to a simultaneous study

92 examining tree sway dynamics (Granucci et al. 2013). Anemometers were monitored with a

93 Campbell Scientific CR9000X datalogger at a rate of 10Hz. Nocturnal data from August 2009 to

94 December 2010 are analyzed here. In all, the data set represents 2000 hours of nighttime data

95 over 215 nights. 30 minute average wind speeds at the 21.4 meter height range from 0.15 to 3.97

$96 \mathrm{~m} / \mathrm{s}$. 49\% of data immediately above the canopy showed calm to weak winds, defined as less

97 than $1.0 \mathrm{~m} / \mathrm{s}$. If this definition is expanded to $2.0 \mathrm{~m} / \mathrm{s} 91 \%$ of the data is considered calm

98 conditions. TKE time series were constructed for nocturnal data, beginning one hour after sunset

99 and ending one hour prior to sunrise. This period was generally assumed to be stable and free of

100 effects of the transition from convective to stable and vice versa. Discussion of the actual

101 stability conditions sampled during this time period is presented below.

\section{2 a. Duration of Stationarity}

103 Stationary periods were computed to examine the energy penetration into the canopy of this

104 site during stable boundary layers. The duration of stationary periods of TKE was calculated at

105 each of the three sonic anemometer locations following the techniques of Nappo et al. (2010), 
106 using a "double mass balance" method. To do this, changes are identified between the slopes of

107 two different time series, $S_{q}$ and $S_{q}^{p} . S_{q}$, is the cumulative sum of some variable, $q$ :

$$
S_{q}\left(t_{i}\right)=\sum_{j=1}^{i} q\left(t_{j}\right)
$$

109 with slopes between consecutive points $\psi$ :

$$
\psi_{i}=\frac{s_{q}\left(t_{i-1}\right)-s_{q}\left(t_{i}\right)}{t_{i-1}-t_{i}}
$$

$111 S_{q}^{p}$ is a linearly extrapolated series computed as a straight line with a slope equal to the that

112 between points $t_{n}$ and $t_{n+1}$ where $j$ is the starting point of the subseries:

$$
S_{q}^{p}\left(t_{i}\right)=S_{q}\left(t_{i-1}\right)+\frac{S_{q}\left(t_{j}\right)-S_{q}\left(t_{j-1}\right)}{t_{j}-t_{j-1}}\left(t_{i}-t_{j}\right)
$$

114 A significant change in slope of the cumulative variable $S_{q}$ implies a change in the mean value of

115 that variable. Thus, the duration of stationarity, $d$, or how long the record of a variable has a

116 constant mean, is defined when the absolute value of the difference of the measured and

117 extrapolated TKE slope exceeds some value $\sigma_{\psi i} . \sigma_{\psi i}$ is calculated as the standard deviation of the

118 individual slopes in the time period being tested:

$$
\sigma_{\psi i}=\sqrt{\frac{1}{i-j} \sum_{i}^{j}\left(\psi_{i}-\mu\right)^{2}}
$$

120 where, $\mu$ is the mean of $\psi$ values between $i$ and $j$. In this way, every significant change in slope 121 represents a change in "weak" first-order stationarity.

122 The process works as follows. Starting with $i=3$ and $j=2$. The values of $S_{q}\left(t_{i}\right) S_{q}^{p}\left(t_{i}\right), \psi_{i}$,

123 and $\sigma_{\psi i}$ are computed for increasing values of $j$. If the difference $S_{q}^{p}-S_{q}$ exceeds $\sigma_{\psi i}$ the

124 duration $d=j-i$, and the process restarts with $i=j$ and $j=i-1$. This algorithm is implemented in

125 Python version 2.7 and code is available from the authors upon request.

126 For this study, $q$ represents turbulence kinetic energy, $e$, defined as: 


$$
\bar{e}=\frac{1}{2}\left(\overline{u^{\prime} u^{\prime}}+\overline{v^{\prime} v^{\prime}}+\overline{w^{\prime} w^{\prime}}\right)
$$

128 where the 'indicates the turbulent component of each vector wind component and the overbar

129 represents a time average. Figure 1 shows an example of the cumulative TKE $\left(S_{e}\right)$ for the night

130 of September 3-4, 2009. Values are normalized to a cumulative sum of unity for display

131 purposes because the value of TKE is much less in the mid- and lower- canopy regions. The

132 inset graph shows a subset of data and the changes in slope identifying the duration of

133 stationarity, along with the lines for $S_{e}^{p}$. When utilizing this technique it is important to

134 recognize that the shortest possible duration of stationarity is the variable time series resolution,

135 defined here as the integral times scale after (Nappo et al., 2010). This is because in [3], $t_{i}-t_{j}$

136 cannot be smaller than the time resolution of the variable of interest. Therefore, in the following

137 discussion, the integral time scale is equivalent to the initial averaging time represented by the

138 overbar in [5]. This definition varies from some uses and is used to represent the time-scale over

139 which the integration is occurring. 


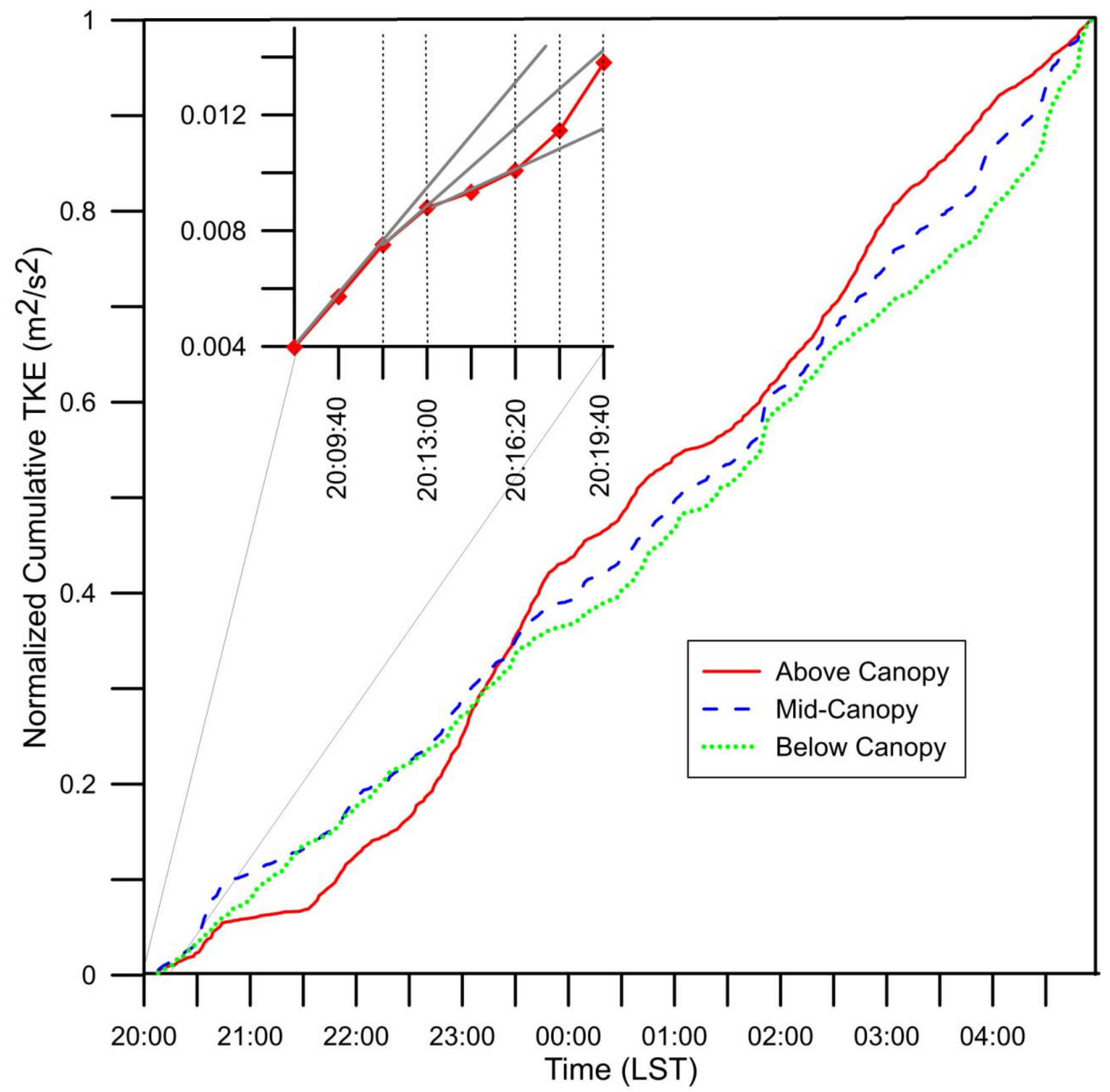

141 Figure 1: Normalized cumulative TKE for the night of September 3-4 2009, for a 100 second averaging time. Values are

142 normalized to 1 for display purposes. The solid line is the above canopy measurement. The dashed line is the mid-canopy

143 measurement. And the dotted line is the below canopy measurement. The inset graph represents the first 700 seconds of

144 the data period with dotted vertical lines indicating the durations found by the change in slope method discussed above.

145 In this case the durations are 200s, 100s, 200s, 100s, and 100s. The solid gray lines represent the predicted time series $S_{e}^{p}$, 146 for each duration. 
148 To compare different turbulent regimes we introduce a stationarity fraction factor, $S_{F R A C}$,

149 computed as

150

$$
S_{F R A C}=\frac{n}{\frac{T}{t_{i}}}
$$

151 Where $n$ is the number of periods of stationarity, $T$ is the total length of the record in seconds,

152 and $t_{i}$ is the integral time scale as discussed above. $n$ is computed as how many periods of

153 stationarity, $d$, of $S_{e}$ are identified during a data record as discussed above, and is representative

154 of how often the mean TKE changes its magnitude. That is, each change in slope marks the end

155 of a stationary period and the start of a new "run" of a stationary signal. $S_{F R A C}$ is a dimensionless

156 value which represents how often during a measurement period turbulence levels change. By

157 definition, $S_{F R A C}$ values can range from 0 to 1 . A value of 1 would indicate the entire record

158 length was non-stationary, and therefore highly intermittent, because no two consecutive time

159 periods had the same first order statistics. A value of 0 would indicate the entire record length

160 was stationary and no intermittency was experienced. Neither extreme is expected to occur, as

161 some level of turbulence will always be present. The stationarity fraction is a linear function of

162 the number of stationary subsets found in a given data record. But it is an exponentially

163 decreasing function of the mean duration for the data record because as the mean duration, $\bar{d}$,

164 increases, the number of possible periods decreases at an exponential rate. For example, in a

1653600 second data record there can be 36 one hundred second periods, 18 two hundred second

166 periods, 12 three hundred second periods, 9 four hundred second periods and so on. $S_{F R A C}$ can be

167 found for any length data record, $T$.

168 It is important to note here the meaning of intermittency in the context of this work.

169 Classically, intermittency means flow that experiences turbulence at some times and not at 
170 others. Strictly using this definition, however, does not work well in the boundary layer

171 environment because some level of turbulence, defined as a deviation from the mean, will always

172 be present. Therefore in this environment, the flow always experiences turbulence. Thus, we

173 define intermittency as a change in first order turbulence statistics. This is an extension of the

174 definitions used in current boundary layer research, such that the turbulent "bursts" and (e.g.

175 Doran 2004) intervening periods are identified when there are changes in the first order statistics.

176 By computing, $d$ (and subsequently $n$ ), using a criteria of one standard deviation as discussed

177 above, intermittency is thus a measure of how often the turbulence level changes in the data

178 record.

$179 S_{F R A C}$ is similar to the intermittency factor defined by Howell and Sun (1999). But it is more

180 universal since it does not consider the overall value of turbulent activity, but rather how often

181 turbulent activity changes. Thus it allows a comparison of intermittency between two data

182 records with different overall turbulent levels. In this way $S_{F R A C}$ is more akin to the turbulent

183 event fraction of Doran (2004), but further avoids the need to introduce an arbitrary turbulence

184 threshold value. A choice of integral time scale, however, is still necessary, although this could

185 be considered more universal values. Additionally, the threshold used to determine slope

186 changes, $\sigma_{\psi i}$, could also be changed to some multiple (e.g $2 \sigma_{\psi i}$ or higher), which would define a

187 turbulent burst as a larger change in statistics.

\section{3. Results}

189 a. Descriptive Long Term Statistics

190 Durations were calculated for each nocturnal period, and a nightly mean duration $(\bar{d})$ was 191 computed for each night, where: 


$$
\bar{d}=\frac{\sum_{i=0}^{i=n} d}{n}
$$

193 and $d$, and $n$ are as defined previously. Durations were computed for integral times scales $\left(t_{i}\right)$

194 ranging from 10 seconds to 5 minutes. This range was chosen to represent values extending 195 from shorter than the co-spectral gap (Vickers and Mahrt 2003) to a reference averaging time 196 commonly used in nocturnal canopy studies (e.g. Dupont and Patton 2012).

197 The dependence on of mean duration with choice of $t_{i}$ is shown in Figure 2. Mean

198 duration increases linearly with $t_{i}$, although the rate of increase varies with canopy height with a 199 slope of 3.5 above the canopy, 3.2 within the canopy, and 2.7 below it. The linear increase is 200 expected because of the restriction that $d$ cannot be smaller than $t_{i .}$ The differences in the rate of 201 increase is discussed in section 4. Figure 2 also shows that in general, when $t_{i}>60$ seconds, the 202 duration of TKE stationarity decreased with canopy depth. That is, the longest periods of 203 stationarity were seen above the canopy. This persistence decreases at the mid-canopy level, and 204 the shortest durations are seen below the canopy. When $t_{i}<60 \mathrm{~s}$ the mean duration at the above 205 canopy and mid-canopy levels are approximately equal. In terms of total range (not shown), 206 with $t_{i}>60 \mathrm{~s}$ mean nightly duration ranges from approximately $2 t_{i}$ to $10 t_{i}$, with $t_{i}<60 \mathrm{~s}$ the 207 minimum nightly duration remains at $\sim 2 t_{i}$ for all height levels, but the maximum value shows no 208 relationship with $t_{i}$ (not shown). Figure 2 also shows the variability seen across all 215 nights is 209 greatest at the mid-canopy level. 


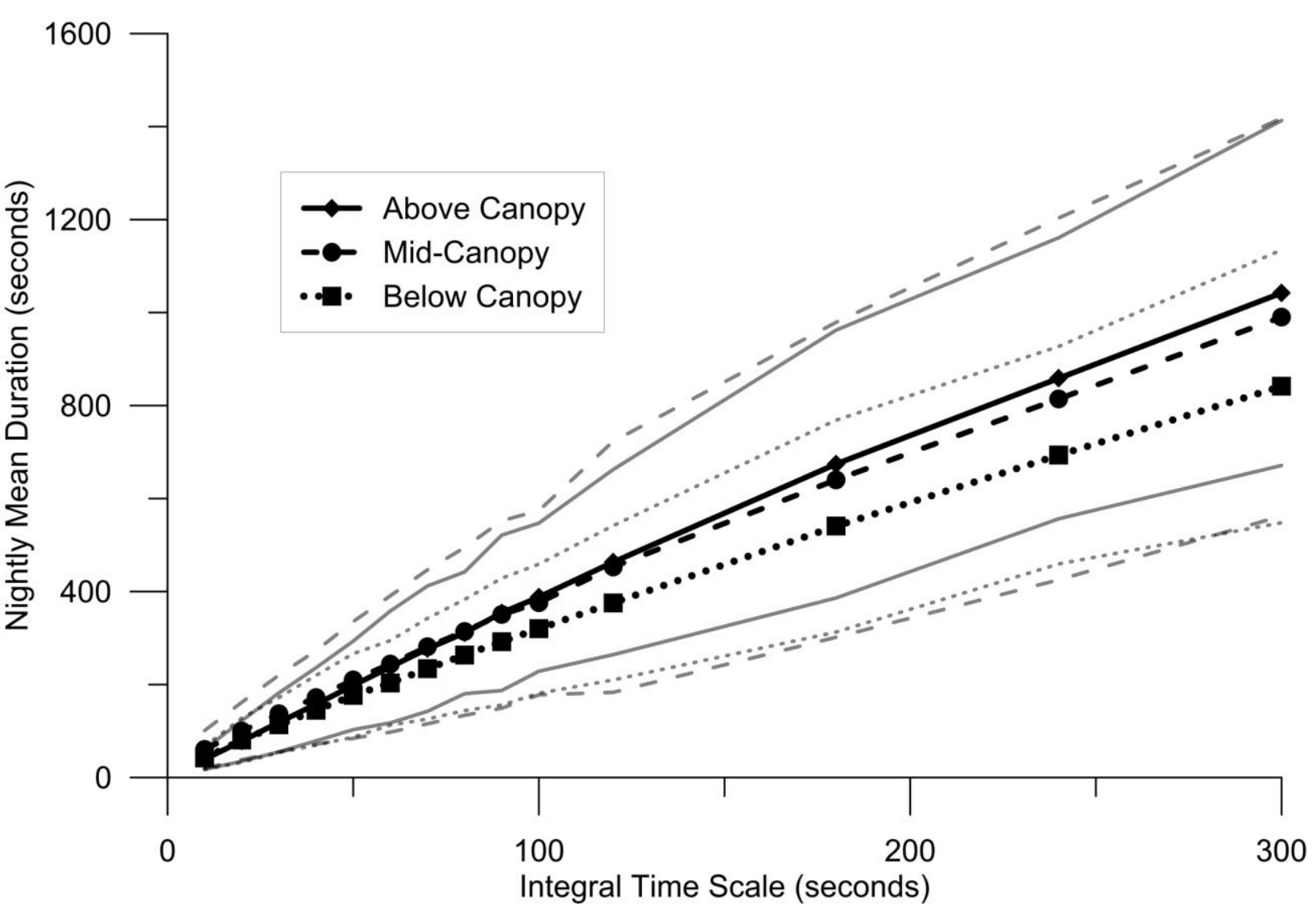

211 Figure 2: Dependence of mean nightly duration (i.e. average length of a stationary data run) on choice of averaging time.

212 Solid line is above canopy, dashed line is mid-canopy, and dotted line is below canopy. Light gray lines indicate one

213 standard deviation around the nightly means.

214 When looking at the length of durations, the number of nights where any single value of

$215 d$ was 30 minutes or longer increases nearly linearly with the chosen integral time scale, until

$216 \mathrm{t}_{i}=240$ seconds, with $\mathrm{t}_{i}>240$ seconds no additional long periods are identified (not shown). Also,

217 the integral time scale increases, so does the probability of finding a stationary data run that lasts

218 for 30 minutes or longer, but the specific relationship varies with height. For shorter integral time

219 scales (< 180 seconds) the highest probability of TKE remaining stationary for more than 30

220 minutes is at the mid-canopy level. The least number of nights with longer periods of persistence

221 is seen below the canopy. This is consistent with the shorter $\bar{d}$ observed below canopy as shown

222 in Figure 2. 
Figure 3 shows the mean $S_{F R A C}$ for all 215 nights with increasing integral time scales. The

224 above canopy mean nightly $S_{F R A C}$ does not vary with choice of integral time scale. The mid-

225 canopy mean nightly $S_{F R A C}$ increases from 0.22 to 0.35 with increasing $t_{i, \text {. The below-canopy }}$

226 mean nightly $S_{F R A C}$ increases from 0.28 to 0.4 with increasing $t_{i}$. At both the mid- and below-

227 canopy heights the rate of increase slows when $t_{i}$ is longer than 120 seconds. $S_{F R A C}$ is greatest

228 above canopy for short time scales and greatest below canopy for longer time scales.

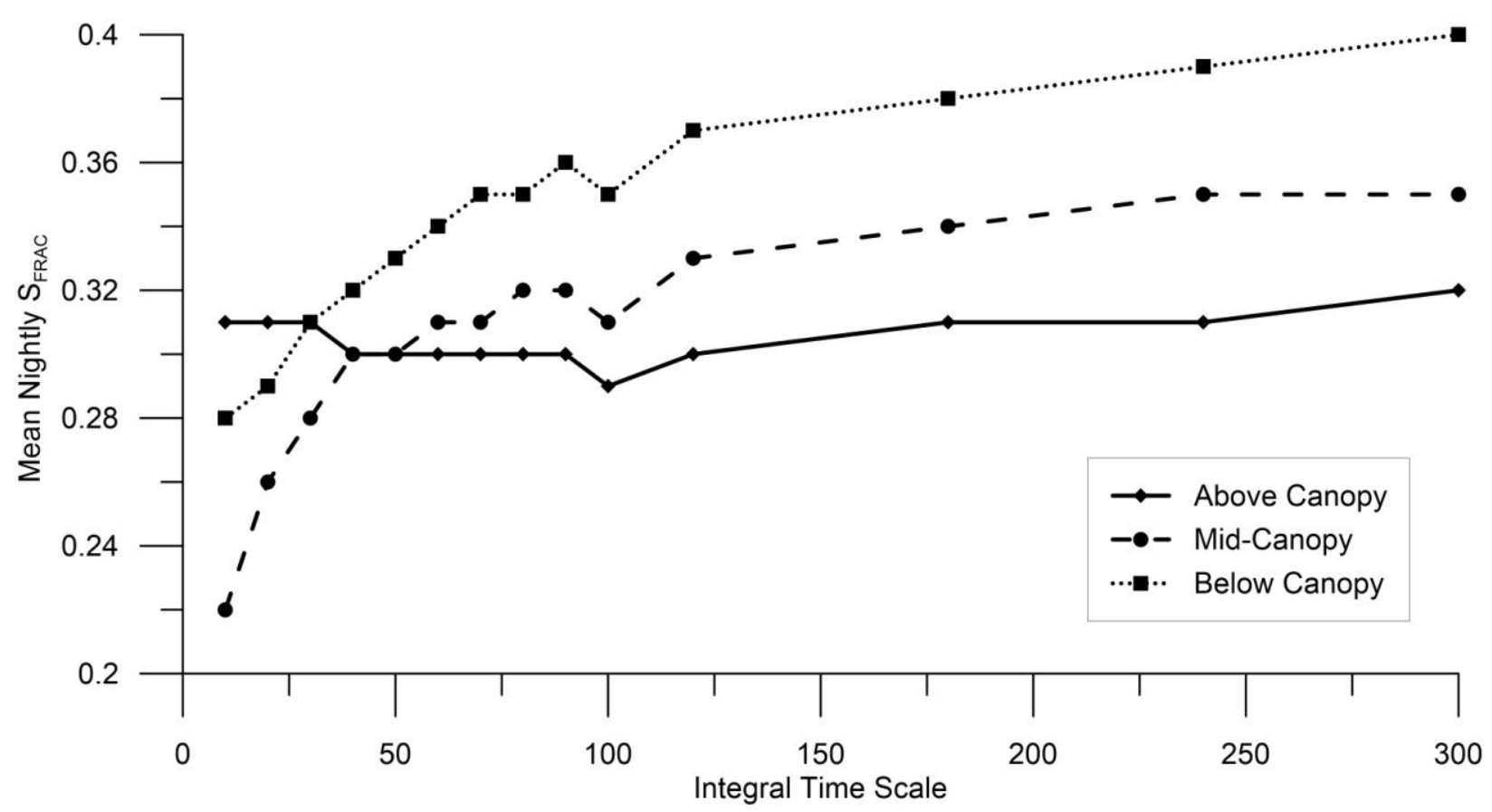

230 Figure 3: Average Nightly $\mathbf{S}_{\mathrm{FRAC}}$ versus integral time scale for all 215 nights. Solid line is above canopy, dashed line is

231 mid-canopy, and dotted line is below canopy.

232 Figure 4 shows nightly values of $\bar{d}$ and $S_{F R A C}$ computed using $t_{i}=100$ s for all 215 nights

233 as a function of friction velocity, $\mathrm{u}^{*}$. The value of $t_{i}=100 \mathrm{~s}$ was chosen for two reasons: it marks

234 a transition as shown in Figure 3, and it is consistent with other work, as this is a commonly used

235 time to filter submesoscale motions in flux analysis (e.g. Klipp and Mahrt, 2004 and others).

236 Similar relationships were seen for other values of $t_{i}$. For all measurements the $\mathrm{u}^{*}$ value is

237 computed from the top sonic. Figure 4 also shows the results of calculating $\bar{d}$ and $S_{F R A C}$ above 
the canopy for each hour of data rather each full night. The same relationship and thresholds are

239 observed for hourly data record lengths as for nightly data. The nightly stationarity fraction

240 ranges in values from a minimum of 0.063 observed mid canopy on September 2, 2010 to a

241 maximum of 0.53 observed mid-canopy on January 8, 2010. A weak linear function exists

242 between $\mathrm{S}_{\mathrm{FRAC}}$ and $\mathrm{u}^{*}$ at the above and mid canopy heights (slope $=0.12$ and $0.10, \mathrm{r}^{2}=0.22$ and

2430.14 respectively). Below the canopy, a linear regression shows no correlation $\left(r^{2}=0.00001\right)$ and

244 a slope of -0.003 showing no trend exists below the canopy. Fitting a line with both $\mathrm{u}^{*}$ and

$245 \mathrm{~S}_{\mathrm{FRAC}}=0$, results in a nearly identical line for all three heights with a slope of $\sim 0.6$ and $\mathrm{r}^{2}$ values

246 ranges from 0.4 to 0.5 . When comparing the nightly $S_{F R A C}$ with height within the canopy, the

247 strongest correlation is seen between above- and mid- canopy levels with a linear regression

248 having an $r^{2}=0.7$. The correlation is weaker when comparing mid- to below-canopy $\left(r^{2}=0.53\right)$

249 and weakest between the above- and below-canopy measurements $\left(r^{2}=0.37\right)$.
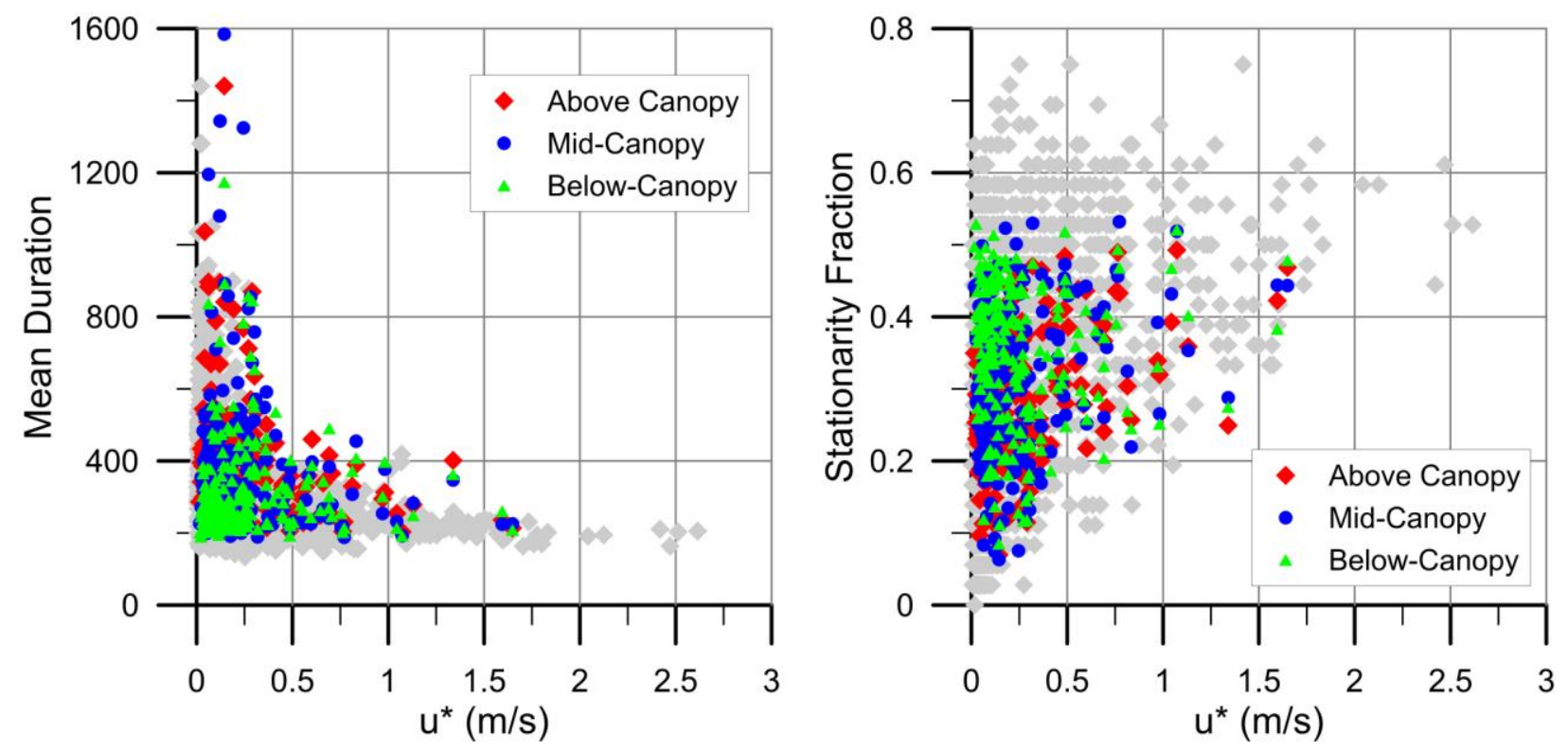

Figure 4: Nightly mean duration, $\bar{d}$, versus mean friction velocity, $\mathrm{u}^{*}$, (left) and nightly stationarity fraction, $S_{\text {frac }}$, versus

252 mean friction velocity (right) for measurements above canopy (diamonds), at mid-(circles) and below (triangles)- canopy

253 heights. One point for each night is shown. The grey symbols are computed hourly, rather than nightly for above canopy

254 measurements from the entire dataset (2000 hours). 
An example of typical distributions of $d$ in a single night for a $t_{i}$ of 100 seconds is shown

256 in Figure 5. It demonstrates that the number of periods with short durations dominates. At each

257 height there are some periods where TKE stays stationary for 5 minutes or more, but relatively

258 few times where TKE remains stationary for 15 minutes or more. This general pattern of each

259 night being dominated by short periods of stationarity and a decrease of the occurrence

260 frequency of longer periods of stationarity is consistently observed for all nights and all values of $261 t_{i}$ 

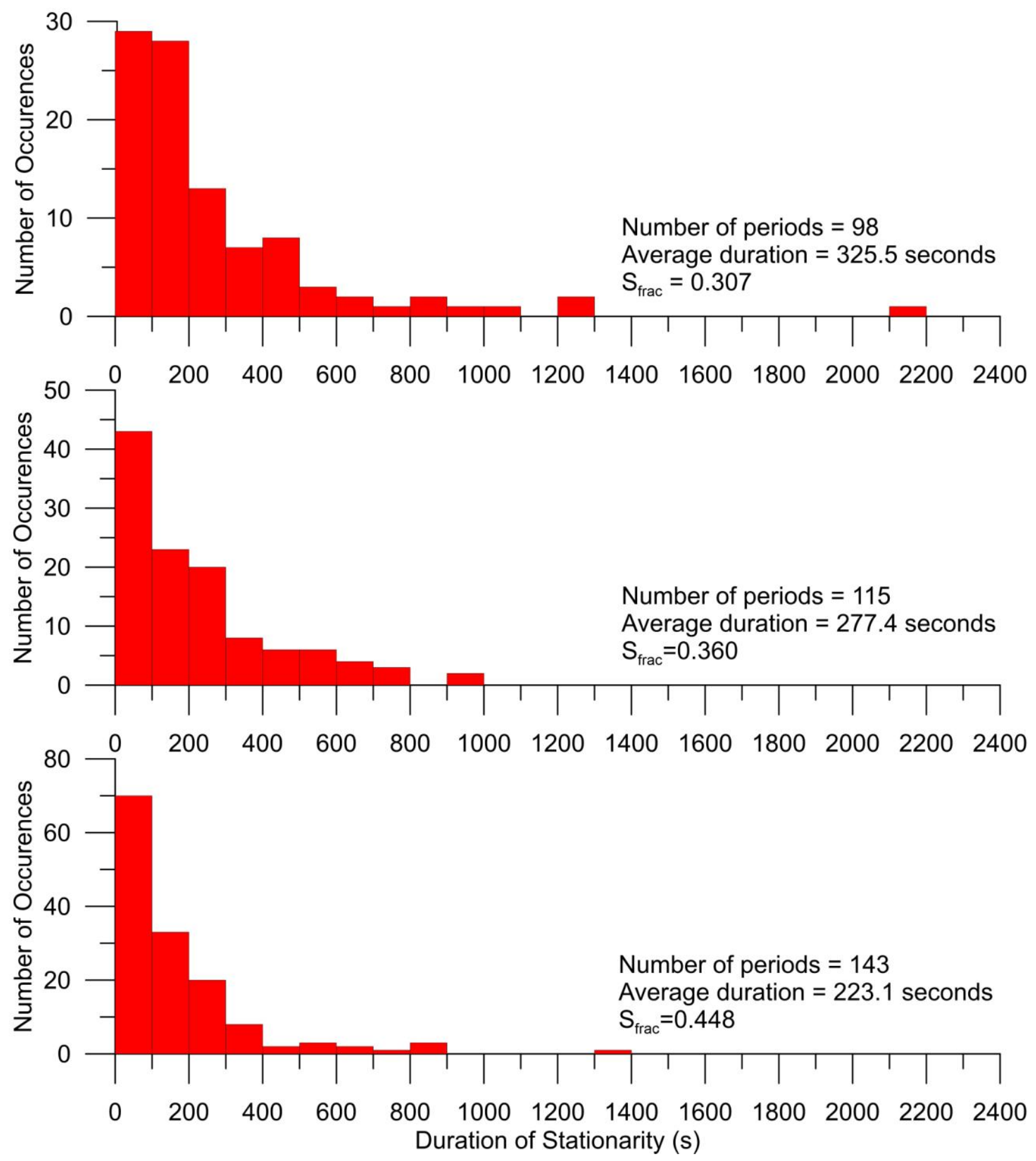

264 Figure 5: Typical distributions of durations for the night of September 3-4 2009. Total data record length is 31919

265 seconds (8 hours and 52 minutes) and durations were computed with a base averaging time of 100 seconds. Upper panel is

266 above canopy, middle is mid-canopy and bottom is below canopy. 
Since the intermittency measure of $S_{F R A C}$ can be computed for any initial length data

268 record, a value was computed for each 30 minute data record. Figure 6 shows the variation of

$269 S_{F R A C}$ over the course of each night. In general, intermittency is highest in first 30 minutes of the

270 nocturnal boundary layer and decreases rapidly in the first three hours. The values level off for

271 the remainder of each night, with the value staying highest below the canopy, indicating more

272 intermittency at the below-canopy level through each nocturnal period as stability increases over

273 the course of each nocturnal period.

274

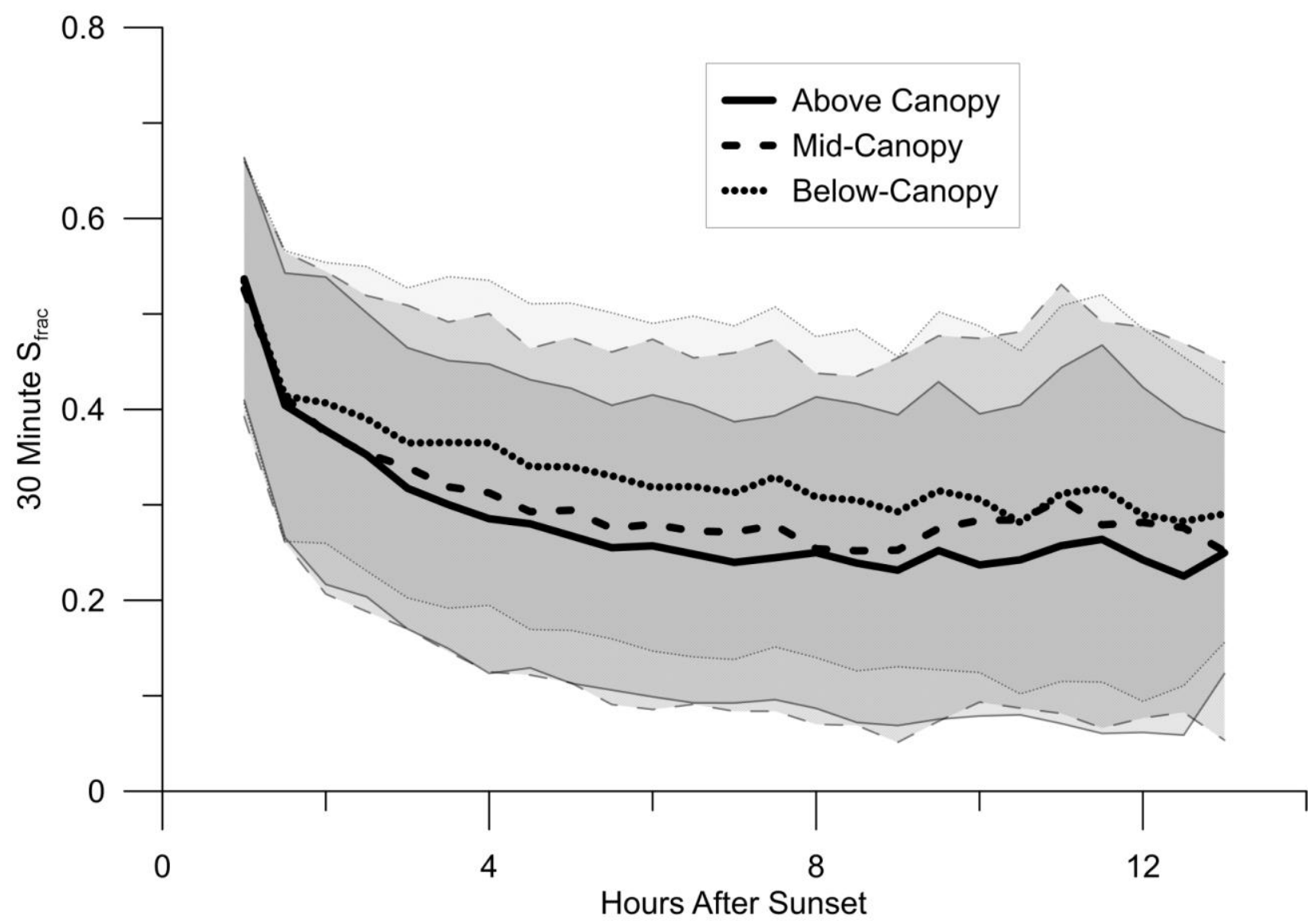

Figure 6: Intermittency $\left(S_{\text {frac }}\right)$ over time for a 30 minute data runs starting 1 hour after sunset. The solid line is above

277 canopy, dashed is mid-canopy, and dotted is below-canopy. The shading indicates one standard deviation of the mean of 278 all 215 nights. 


\section{b. Stability Dependence}

280 Because all measurements are in the canopy roughness sublayer (CRSL) the most commonly

281 used measure of stability, the Bulk Richardson number, could not be computed reliably. Instead

282 the local stability parameter, $\xi$, is used as an indicator of stability conditions. $\xi$ is computed as (z-

$283 \mathrm{~d} / \mathrm{L}$, where $\mathrm{d}$ is the displacement height estimated as $0.66 \mathrm{~h}$, where $\mathrm{h}$ is the average canopy

284 height. $\xi$ was computed at the top sonic, and each 30 minute measurement period was classified

285 as unstable $(\xi<-0.1)$, neutral $(-0.1<\xi<0.1)$ or stable $(\xi>0.1)$. The overall stability regime is best

286 characterized by the forcing conditions at the top of the canopy even if below canopy layers are

287 decoupled from the upper canopy mechanical turbulence. As expected, the majority of the data

288 was considered stable (3058 half hour periods, $75 \%$ ), although 922 half hour periods (22\%) were

289 identified as unstable with the majority of $\xi$ values ranging from -0.1 to -5000.125 half hour

290 periods were identified as neutral (3\%). Most of the unstable periods occurred in the Fall and

291 Winter months. In almost all cases, once unstable conditions were identified, the data remained

292 unstable for the rest of the night. Often this occurred after 3 AM. There were some nights were

293 no stable conditions were identified at all. These atypical nights will be the subject of future

294 investigations. When neutral conditions were identified they tended to remain so for only $2-3$

295 hours before returning to either stable or unstable conditions. Figure 7 shows histograms of the

29630 minute stationarity factor above the canopy for each stability group, similar distributions were

297 found at mid- and below- canopy levels with the mean shifting slightly as presented above.

298 Stability itself is not an indicator of changing stationary conditions, but the mean $S_{F R A C}$ in stable

299 conditions is higher than in unstable conditions and it is highest in neutral conditions. An

300 ANOVA and paired T-tests indicate that the differences observed between different stability

301 conditions are all statistically significant. 


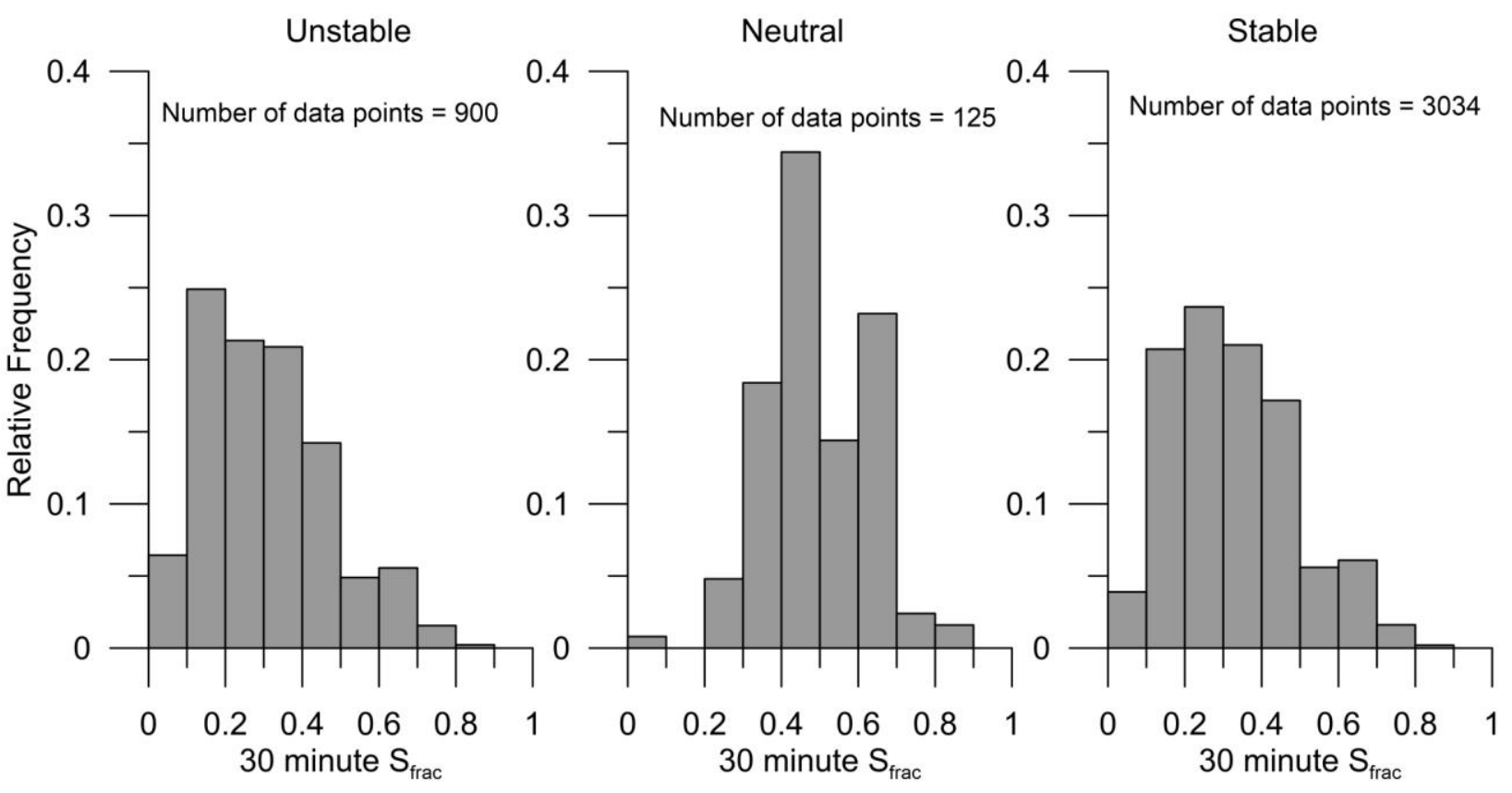

304 Figure 7: Relative frequency of above canopy intermittency factors for different stability conditions. Unstable has a mean $S_{\text {frac }}$ of 0.3 , Neutral has a mean $S_{\text {frac }}$ of 0.5 and Stable has a $S_{\text {frac }}$ of 0.34 .

\section{c. Case Study}

307 In this section we present results in detail for the night of September 3-4, 2009. The

308 cumulative TKE curve and distributions of $d$ for this time period were shown in Figure 1 and

309 Figure 5 respectively. This night represents a typical low wind speed observational period with

3108.5 hours of continuous measurements. The average above canopy wind speed was $0.9 \mathrm{~ms}^{-1}$

311 ranging from $0.2 \mathrm{~ms}^{-1}$ to $1.7 \mathrm{~ms}^{-1}$. Stability was classified using the local stability parameter $\xi$,

312 computed at the top of the canopy. The entire night is stable with $\xi>>0.1$, indicating a fully

313 developed stable boundary layer. Figure 8 and Figure 9 show TKE measured at the beginning

314 and end of the night along with the corresponding durations of stationarity. These two periods

315 were chosen to represent a high intermittency period as indicated by an above canopy 30 minute

$316 S_{F R A C}$ of 0.78 and a low intermittency period as indicated by an above canopy $S_{F R A C}$ of 0.11 
317 respectively. The effects of canopy elements on the intermittency characteristics are seen in

318 these figures. As momentum is transported down through the canopy, the mid-canopy shows the

319 highest $S_{F R A C}$ during the low intermittency period and the lowest $S_{F R A C}$ during the high

320 intermittency period. This suggests when conditions are stationary above the canopy, energy is

321 transported downwards, causing more disruption in the first order statistics. Intermittent

322 conditions above the canopy also indicate intermittent conditions within and below the canopy.

323 For comparison, the method was applied to this night with a threshold of $2 \sigma_{\psi i}$. As would be

324 expected, the results show a longer duration and a lower $\mathrm{S}_{\mathrm{FRAC}}$. But, the relationship between the

325 three heights and overall change of $\mathrm{S}_{\mathrm{FRAC}}$ over the course of the night stay the same. 

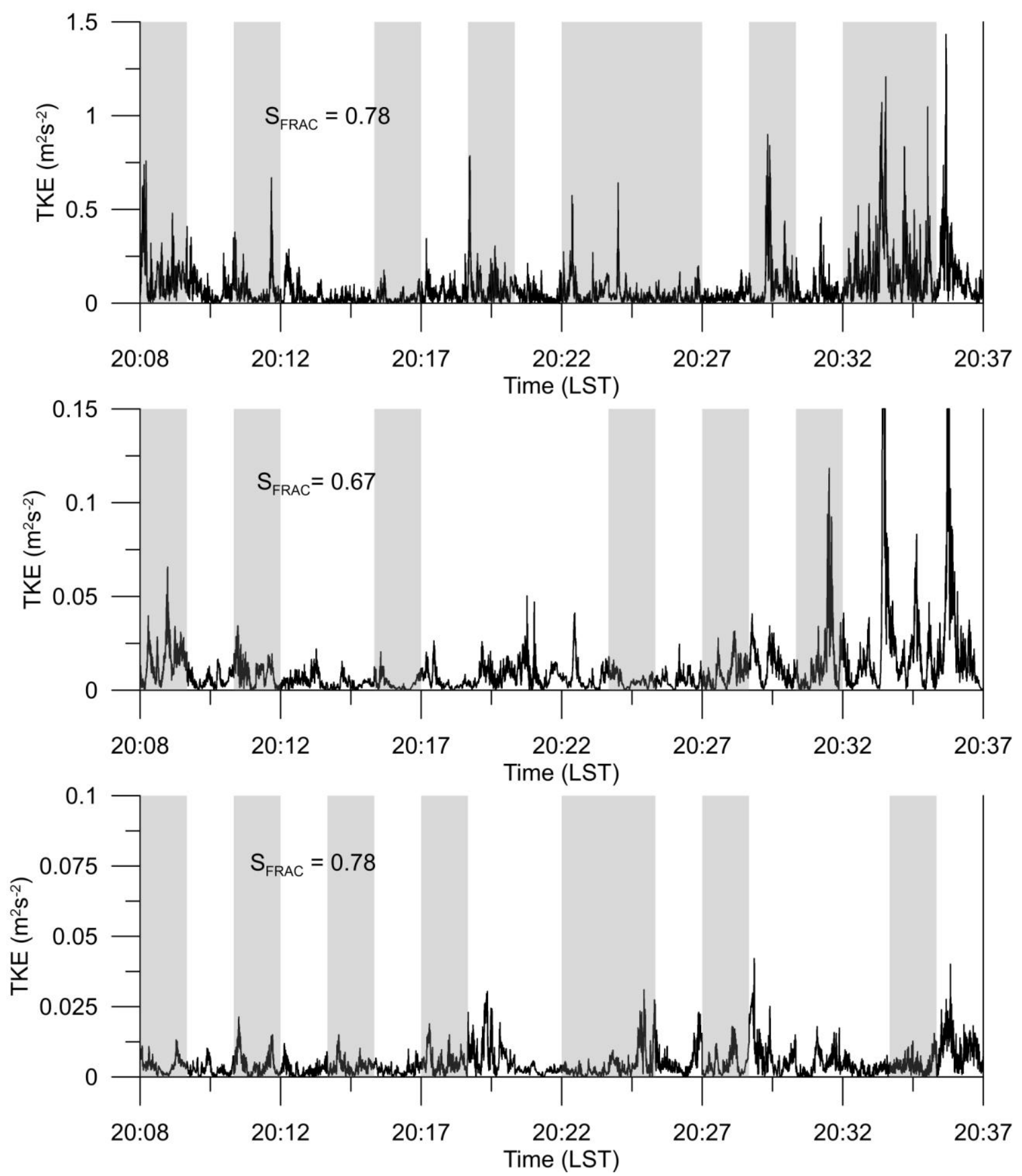

327 Figure 8: TKE for the first 30 minutes measured on September $3^{\text {rd }}, 2009$. Grey and white segments indicate where

328 changes in the slope of, $S_{e}$, were identified. Top panel - above canopy, Middle panel - mid-canopy level, Bottom panel 329 below live crown. 

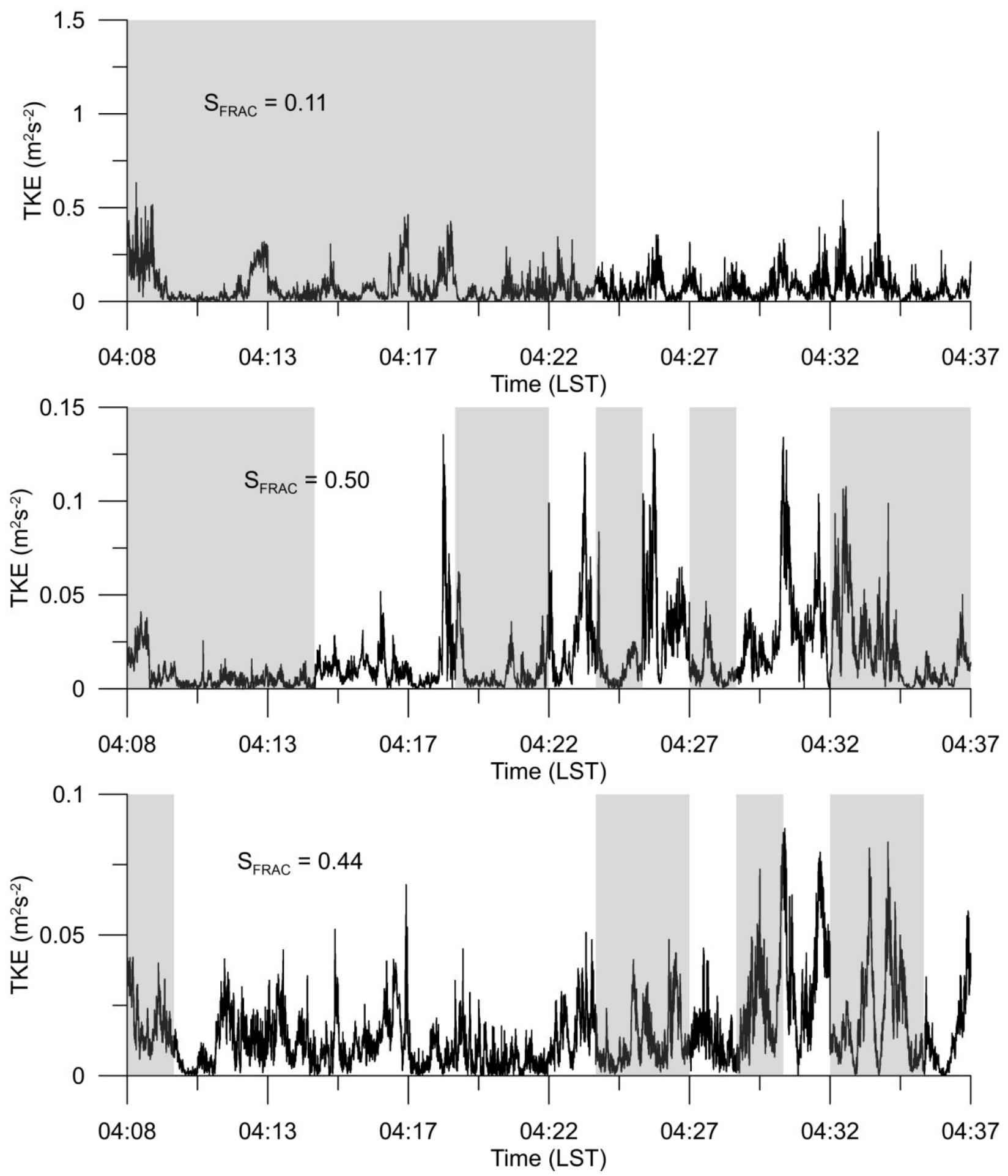

331 Figure 9: As for figure 8 for the 30 minutes from 4:08 AM to 4:38 AM on September $4^{\text {th }}, 2009$. 


\section{Discussion}

333 Overall, in the nocturnal canopy roughness sublayer, TKE can remain stationary for periods

334 ranging from the averaging time scale to periods upwards of one hour, although the latter is rare.

335 As shown in Figure 2, with respect to height in the canopy, for integral times greater than one

336 minute the longest periods of stationarity were seen just above the canopy, where interaction of

337 winds and roughness elements provides the most opportunity for mechanical generation of

338 turbulence. This decreases at the mid-canopy level where the sheltering effect of branches and

339 needles reduce the wind energy. The shortest durations are seen below the canopy where wind

340 speeds tend to be more light and variable. Above the canopy, it is most likely that TKE remains

341 stationary for a period of twice the chosen averaging time. While in and below the canopy space,

342 it is most likely that TKE will only remain stationary for the chosen averaging time. When an

343 averaging time of less than one minute is used, the top and mid canopies levels have the same

344 mean duration characteristics. This indicates that even when using extremely short averaging

345 times, the assumption of stationarity can be violated when computing traditional 30 minute

346 fluxes. Despite this, every night had at least 1 period (most often more) of TKE stationarity

347 lasting for 15 minutes or longer, and these long periods are most likely to occur at the above 348 canopy level.

349 As seen in Figure 4, a wide range of conditions are possible in the nocturnal CRSL. At this

350 site, TKE is most likely to remain stationary for some portion of the night when $\mathrm{u}^{*}$ values are

351 less than $0.5 \mathrm{~ms}^{-1}$. Above the canopy, when $\mathrm{u}^{*}$ exceeds this value, $S_{F R A C}$ is linearly correlated

352 with a slope of 0.38 . For $\mathrm{u}^{*}$ conditions less than $0.5 \mathrm{~ms}^{-1}$ the slope of the line increases to 1.16

353 and the strength of the relationship, as indicated by a linear regression fit statistic, is reduced. No

354 simple relationship with mean wind speed exists for either the mean duration of stationary runs 
355 or the stationarity fraction. Although, in general, as wind speed increases mean duration

356 decreases and intermittency increases. There is a continual increase in intermittency, as measured

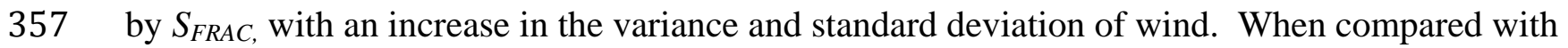

358 higher order statistics (not shown), there is an increase in $S_{F R A C}$ with decreasing skewness and

359 kurtosis of horizontal wind speed until a threshold value of $S_{F R A C}=0.2$, above which, $S_{F R A C}$

360 remains constant with kurtosis and skewness of horizontal wind speed, at all heights. This

361 means that a period with a positively skewed windspeed distribution is more highly intermittent

362 with regards to turbulence than a non-skewed windspeed distribution. This indicates that

363 turbulence intermittency is related to higher order statistics. Furthermore, no long-term

364 relationship was observed with either wind direction or season, indicating that the causes for

365 intermittent turbulent events is either localized or isolated in time. This is in agreement with

366 other studies, but given the length of this data set it is worth noting.

367 When comparing intermittency between the three measurement locations, it is observed that

368 the occurrence of intermittent conditions above the canopy is a poor predictor of intermittent

369 conditions within or below canopy. But intermittent conditions at mid-canopy and below canopy

370 levels are highly correlated, meaning that when intermittent turbulence exists at mid-canopy it

371 also exists below canopy and vice versa. The highest variability is seen at the mid-canopy level.

372 Further analysis is needed to identify the potential causes of the observed bursts in TKE.

373 When applied to longer term eddy covariance data sets, this method could help identify and

374 remove non-stationary records of varying time durations as opposed to current methods which

375 eliminate an entire average period if it is flagged as non-stationary. Thus preserving a larger

376 portion of the original dataset and improving the accuracy of measured fluxes. As an example,

377 the night of September 3-4 2009 was used with the stationarity tests of (Foken and Wichura 
378 (1996) as presented in Cava et al. (2014). This test assesses the variability of shorter periods

379 within each 30 minute sample by computing a ratio of the variability of the 5 minute fluxes to the 380 mean 30 minute fluxes. If the ratio is less than the threshold of $30 \%$ then the time series is

381 considered to be strongly stationary. For this night, using a reference flux of w`T`, all above 382 canopy 30 minute runs would be identified as stationary, but 5 of 17 the mid-canopy runs (29\%) 383 and 15 of 17 below-canopy runs (88\%) of the below canopy runs would fail the stationary test.

384 When loosening the $\mathrm{RN}$ threshold to the more operational threshold (Cava et al, 2014) of 50\%, 385 an additional 2 runs are considered stationary at mid-canopy and an additional 3 runs are 386 considered stationary below canopy. Figure 10 shows the result of calculating vertical heat flux 387 using the traditional technique with 5 minute subintervals and using the duration, $d$, as a 388 changing sub-interval time. The major differences are seen early in the evening (corresponding 389 to the highly intermittent shown in Figure 8) where a stronger downward heat flux is found and 390 late at night (corresponding to the low intermittency period shown in Figure 9) when a less 391 intense downward heat transfer is seen. 


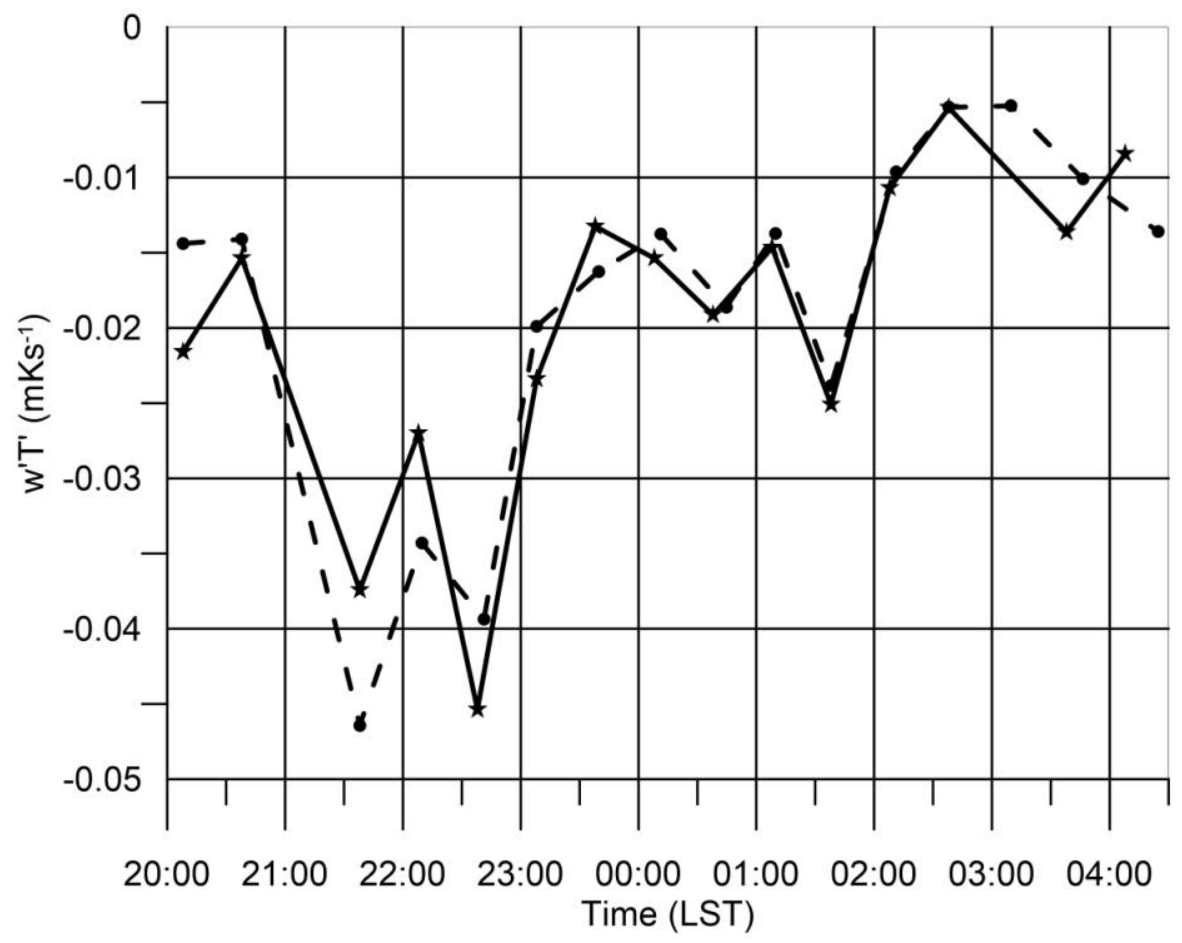

392

Figure 10: Vertical heat flux above canopy for night of Sept 3-4. Solid line is traditional 30 minute computation with 5 minute subintervals and dashed line is a $\mathbf{3 0}$ minute value using a variable sub-interval period equal to the duration of stationarity.

\section{Conclusions}

We have presented a technique for measuring intermittency in the stable boundary layer, when intermittency is considered a change in the statistics. The results presented here have been based on turbulence kinetic energy, but the technique could be applied to any non-negative

400 variable. This technique has value for the future understanding of stable boundary layers.

401 Specifically, we conclude that at night in CRSL the assumption of stationarity is only true for 402 periods < 1000 seconds and really can only be assumed reliably for periods <200s. Additionally, 403 intermittency is highest at the beginning of a nocturnal period. Here we attempted to eliminate 404 the transitional periods between day and night by removing the first hour after sunset from the 405 analysis, however a change in intermittency is still observed as the stable boundary layer grows 
406 (Figure 5). This indicates that in a forested environment the effects of the residual layer persist

407 at until at least two hours after sunset, and that the highest potential for intermittency exists in

408 periods transitioning from one stability regime to another. Finally, it is possible to have data runs

409 of stationary TKE that last longer than one hour, although they are rare. The actual duration of

410 stationarity, however, is dependent on the initial Reynolds averaging time which has broader

411 implications for flux calculations at night and within canopies.

412 Given the length of the study period and the wide variation in conditions observed, these

413 general observations can be useful for parameterizing models of CRSL dispersion, vertical flux

414 and advection of scalars. Furthermore, these methods can provide some additional detail on

415 fluxes within the canopy, while still maintaining the underlying assumption of stationarity.

416 Additionally this technique has the potential to provide measures of energy penetration into the 417 canopy.

\section{6. Acknowledgements}

419 This work was funded by NSF awards ATM-1117922, ATM-084014, and ATM-0840191.

420 The authors would also like to thank graduate students David Granucci and Atticus Finger for

421 their work on site installation and data management. Additional thanks also goes to John Lee,

422 Bryan Dale, David Hollinger and the rest of the Howland Forest staff for their invaluable on-site 423 maintenance and troubleshooting. 


\section{References}

425 Alekseychik, P., I. Mammarella, S. Launiainen, Ü. Rannik, and T. Vesala, 2013: Evolution of the nocturnal decoupled layer in a pine forest canopy. Agricultural and Forest Meteorology, 174, $15-27$.

428 Aubinet, M., 2008: Eddy covariance $\mathrm{CO}_{2}$ flux measuremetns in noctural conditions: An anlaysis of the problem. Ecological Applications, 18, 1368-1378.

430 Baldocchi, D. D., 2003: Assessing the eddy covariance technique for evaluating carbon dioxide exchange rates of ecosystems: past, present and future. Global Change Biology, 9, 479-

433 Belcher, S.E., Harman, I.N. and Finnigan, J.J., 2012. The Wind in the Willows: Flows in Forest 434 Canopies in Complex Terrain. Annual Review of Fluid Mechanics, 44, 479-504.

435 Cava, D., Schipa, S. and Giostra, U., 2005. Investigation of Low-Frequency Perturbations Induced by a Steep Obstacle. Boundary-Layer Meteorology, 115, 27-45.

437 Cava, D., A. Donateo, and D. Contini, 2014: Combined stationarity index for the estimation of 438 turbulent fluxes of scalars and particles in the atmospheric surface layer. Agricultural and

440 Cullen, N., K. Steffen, and P. Blanken, 2007: Nonstationarity of turbulent heat fluxes at Summit, Greenland. Boundary-Layer Meteorology, 122, 439-455.

442 Doran, J., 2004: Characteristics of Intermittent Turbulent Temperature Fluxes in Stable Conditions. Boundary-Layer Meteorology, 112, 241-255.

444 Dupont, S., and E. G. Patton, 2012: Influence of stability and seasonal canopy changes on 445 micrometeorology within and above an orchard canopy: The CHATS experiment. 446 Agricultural and Forest Meteorology, 157, 11-29. 
447 Dwyer, M.J., Patton, E.G. and Shaw, R.H., 1997. Turbulent kinetic energy budgets from a large-

448 eddy simulation of airflow above and within a forest canopy. Boundary-Layer

$449 \quad$ Meteorology, 84, 23-43.

450 Finnigan, J. J., R. H. Shaw, and E. G. Patton, 2009: Turbulence structure above a vegetation

451 canopy. Journal of Fluid Mechanics, 637, 387-424.

452 Foken, T., Wichura, B., 1996. Tools for quality assessment of surface-based flux measurements.

453 Agricultural and Forest Meteorology 78, 83-105.

454 Foken, T., and B. Wichura, 1996: Tools for quality assessment of surface-based flux

455 measurements. Agricultural and Forest Meteorology, 78, 83-105.

456 Granucci, D., M. Rudnicki, A. Hiscox, D. Miller, and H.-B. Su, 2013: QuantSfracying the effects

457 of freezing on tree sway frequencies. Agricultural and Forest Meteorology, 168, 10-14.

458 Hollinger, D. Y., S. M. Goltz, E. A. Davidson, J. T. Lee, K. Tu, and H. T. Valentine, 1999:

459 Seasonal patterns and environmental control of carbon dioxide and water vapour

460 exchange in an ecotonal boreal forest. Global Change Biology, 5, 891-902.

461 Howell, J. F., and J. Sun, 1999: Surface-Layer Fluxes in Stable Conditions. Boundary-Layer

462 Meteorology, 90, 495-520.

463 Klipp, C.L. and Mahrt, L., 2004. Flux-gradient relationship, self-correlation and

464 intermittency in the stable boundary layer. Quarterly Journal of the Royal

465 Meteorological Society, 130(601): 2087-2103.

466 Leclerc, M.Y., Shaw, R.H., Hartog, G.D. and Neumann, H.H., 1990. The Influence of

467 Atmospheric Stability on the Budgets of the Reynolds Stress and Turbulent Kinetic

468 Energy within and above a Deciduous Forest. Journal of Applied Meteorology, 29,

469 916-933. 
470 Lee, X., 2000. Air motion within and above forest vegetation in non-ideal conditions. Forest $471 \quad$ Ecol Manag, 135, 3-18.

472 Lesnik, G., 1974. Results of measurement of turbulent energy balance components in a layer of 473 vegetation. Izv. Atmos. Oceanic Phys, 10, 652-655.

474 Liang, J., L. Zhang, Y. Wang, X. Cao, Q. Zhang, H. Wang, and B. Zhang, 2014: Turbulence 475 regimes and the validity of similarity theory in the stable boundary layer over complex 476 terrain of the Loess Plateau, China. Journal of Geophysical Research: Atmospheres, 119, $477 \quad$ 2014JD021510.

478 Mahrt, L., 1998: Flux sampling errors for aircraft and towers. Journal of Atmospheric and $479 \quad$ Oceanic technology, 15, 416-429.

480 Mahrt, L., 2010: Computing turbulent fluxes near the surface: Needed improvements. $481 \quad$ Agricultural and Forest Meteorology, 150, 501-509.

482 Mahrt, L., 2014. Stably Stratified Atmospheric Boundary Layers. Annual Review of Fluid $483 \quad$ Mechanics, 46, 23-45.

484 Mahrt, L., S. Jielun, W. Blumen, T. Delany, and S. Oncley, 1998: Nocturnal Boundary-Layer 485 Regimes. Boundary-Layer Meteorology, 88, 255-278.

486 Mahrt, L., Lee, X., Black, A., Neumann, H. and Staebler, R., 2000. Nocturnal mixing in a forest 487 subcanopy. Agricultural and Forest Meteorology, 101, 67-78.

488 Meyers, T.P. and Baldocchi, D.D., 1991. The budgets of turbulent kinetic energy and Reynolds 489 stress within and above a deciduous forest. Agricultural and Forest Meteorology, 53, $490 \quad 207-222$. 
491 Nappo, C., A. Hiscox, and D. Miller, 2010: A Note on Turbulence Stationarity and Wind

492 Persistence Within the Stable Planetary Boundary Layer. Boundary-Layer Meteorology, $493 \quad \mathbf{1 3 6}, 165-174$.

494 Prabha, T. V., M. Y. Leclerc, A. Karipot, and D. Y. Hollinger, 2007: Low-Frequency Effects on 495 Eddy Covariance Fluxes under the Influence of a Low-Level Jet. J. Appl. Meteorol. $496 \quad$ Climatol., 46, 338-352.

497 Salmond, J., 2005: Wavelet analysis of intermittent turbulence in a very stable nocturnal 498 boundary layer: implications for the vertical mixing of ozone. Boundary-Layer $499 \quad$ Meteorology, 114, 463-488.

500 Sun, J., L. Mahrt, R. M. Banta, and Y. L. Pichugina, 2012: Turbulence Regimes and Turbulence 501 Intermittency in the Stable Boundary Layer during CASES-99. Journal of the $502 \quad$ Atmospheric Sciences, 69, 338-351.

503 Sun, J., D. H. Lenschow, L. Mahrt, and C. Nappo, 2013: The Relationships among Wind, 504 Horizontal Pressure Gradient, and Turbulent Momentum Transport during CASES-99. 505 Journal of the Atmospheric Sciences, 70, 3397-3414.

506 Sun, J., and Coauthors, 2002: Intermittent Turbulence Associated with a Density Current Passage 507 in the Stable Boundary Layer. Boundary-Layer Meteorology, 105, 199-219.

508 Sun, J., and Coauthors, 2004: Atmospheric Disturbances that Generate Intermittent Turbulence 509 in Nocturnal Boundary Layers. Boundary-Layer Meteorology, 110, 255-279.

510 Van de Wiel, B. J. H., A. F. Moene, R. J. Ronda, H. A. R. De Bruin, and A. A. M. Holtslag, 511 2002a: Intermittent Turbulence and Oscillations in the Stable Boundary Layer over Land.

512 Part II: A System Dynamics Approach. Journal of the Atmospheric Sciences, 59, 2567$513 \quad 2581$. 
514 Van de Wiel, B. J. H., R. J. Ronda, A. F. Moene, H. A. R. De Bruin, and A. A. M. Holtslag, $5152002 b$ : Intermittent Turbulence and Oscillations in the Stable Boundary Layer over Land.

516 Part I: A Bulk Model. Journal of the Atmospheric Sciences, 59, 942-958.

517 Van de Wiel, B. J. H., and Coauthors, 2012: The minimum wind speed for sustainable turbulence $518 \quad$ in the nocturnal boundary layer. Journal of the Atmospheric Sciences, 69, 3116-3127.

519 Vickers, D., and L. Mahrt, 2003: The cospectral gap and turbulent flux calculations. Journal of $520 \quad$ Atmospheric and Oceanic Technology, 20, 660-672.

521 Vickers, D., and C. K. Thomas, 2013: Some aspects of the turbulence kinetic energy and fluxes

522 above and beneath a tall open pine forest canopy. Agricultural and Forest Meteorology, $523 \quad \mathbf{1 8 1}, 143-151$.

524 Xiao, X., D. Hollinger, J. Aber, M. Goltz, E. A. Davidson, Q. Zhang, and B. Moore Iii, 2004:

525 Satellite-based modeling of gross primary production in an evergreen needleleaf forest.

526 Remote Sensing of Environment, 89, 519-534.

527

528 